\title{
Cathepsin B is involved in the apoptosis intrinsic pathway induced by Bacillus Calmette-Guérin in transitional cancer cell lines
}

\author{
EDUARDO SANDES $^{1}$, CATALINA LODILLINSKY ${ }^{1}$, RUTH CWIRENBAUM ${ }^{1}$, \\ CLAUDIA ARGÜELLES ${ }^{2}$, ALBERTO CASABÉ ${ }^{1}$ and ANA MARÍA EIJÁN ${ }^{1}$ \\ ${ }^{1}$ Research Area from Instituto de Oncología Ángel H. Roffo, Universidad de Buenos Aires, Av. San Martín 5481; \\ ${ }^{2}$ Instituto Nacional de Producción de Biológicos Dr Carlos G. Malbrán, Buenos Aires, Argentina
}

Received August 3, 2007; Accepted September 24, 2007

\begin{abstract}
Bacillus Calmette-Guérin (BCG) is the most effective treatment for superficial and in situ transitional bladder cancer. Although the complete mechanisms for its effect are not fully understood yet, both immunological and direct effects on tumor cells have been proposed. It has been proposed that apoptotic tumor cells could be better inducers of immunity than necrotic ones. Thus, apoptosis of bladder cancer cells could contribute to a global response to BCG. Lysosomal hydrolase cathepsin B (CB) is involved in the apoptotic process and has a key role in breast cancer cell programmed death through the activation of a pro-apoptotic protein BID. Truncated BID participates in the mitochondrial apoptotic pathway that involves the activation of pro-caspase 9. The possibility that CB can be involved in apoptosis of TCC line has not been explored yet. Therefore, we analyzed the participation of CB in BCG-induced apoptosis of human and murine TCC lines. Apoptosis was evaluated by a morphologic assay and $\mathrm{CB}$ activity by a substrate-specific colorimetric method. Expression of CB, BID and pro-caspase 9 was determined by Western blotting. BCG induced apoptosis of murine (MBT2, MB49) and human (T24) TCC lines. An increase in both $\mathrm{CB}$ activity and protein was also observed. The apoptosis of T24 and MB49 cell lines was mediated by activation of pro-caspase 9 and BID, both proteins are involved in mitochondrial apoptosis. Apoptosis and activation of pro-caspase 9 and BID were inhibited by CA074Me (CA), a cell permeable CB inhibitor. Thus, CB is involved in BCG-induced apoptosis of TCC lines, using at least in part the mitochondrial pathway.
\end{abstract}

Correspondence to: Dr Ana María Eiján, Área Investigación, Instituto de Oncología Ángel H. Roffo, Av. San Martín 5481, CP 1417 DTB Buenos Aires, Argentina

E-mail: anamariaeijan@fibertel.com.ar

Key words: transitional cancer cell, Bacillus Calmette-Guérin, cathepsin B, apoptosis, bladder cancer

\section{Introduction}

Intravesical administration of attenuated bacillus CalmetteGuérin (BCG) plays a major role in the treatment and prophylaxis of recurrent superficial and in situ bladder carcinoma (1). Recent meta-analyses have shown that BCG is better than other intravesical chemotherapeutic agents for prevention of tumor recurrence. In addition, BCG is the only intraluminal therapy that has been demonstrated to decrease the risk of tumor progression to muscle invasion (2).

Despite this therapeutic advantage of intravesical BCG, a significant number of patients fail to respond and present disease recurrence or progression (3). Efforts to improve treatment outcomes with BCG depend on a clear understanding of the sequence of events through which BCG exerts its antitumor activity.

The exact mechanism of the anti-tumor activity is not completely understood, but it is well known that BCG evokes an early local immune cell reaction, which includes an increase in the MHC complex and cytokine production and finally in the Th1 cell-regulated cytotoxicity towards TCC (4).

A direct interaction between tumor cells and BCG has also been described. Internalized and degraded BCG has been identified in urothelial cells both in vitro and in vivo (5). BCG induces surface antigen expression on bladder tumor cells (6) and growth inhibition of bladder cancer cell lines in vitro (7). Other mycobacteria have been implicated in apoptosis induction of their target cells $(8,9)$ and the induction of bladder cancer cell apoptosis by INF, which is induced by BCG, has also been documented (10). However, the possibility that BCG can also directly induce apoptosis in bladder cancer cells has not been addressed.

Apoptosis is a physiological process that regulates homeostasis of different tissues by eliminating cells and that is downregulated in tumor cells (11). Initiation and execution phases of apoptosis require the activation of cysteine proteases of the caspase family. Two major pathways of apoptosis have been described: the extrinsic one, which takes place by the activation of the death receptor and is initiated by caspase 8 ; and the intrinsic or mitochondrial one, which involves procaspase 9 activation (12). Cathepsin B (CB), a lysosomal 
hydrolase has recently been involved in the apoptotic process as well $(13,14)$. More recently, it has been reported that CB has a key role in breast cancer cell programmed death through the activation of BID, a proapoptotic member of the Bcl-2 family (15). The possibility that $\mathrm{CB}$ can be involved in apoptosis of bladder cancer cells has not yet been explored. Thus, we analyzed the participation of CB in BCG-induced apoptosis of human and murine bladder cancer cell lines.

\section{Materials and methods}

$B C G$. Living organisms of an attenuated strain of Mycobacterium bovis (Pasteur 1172 P2 strain, containing 2x10 colony forming units-CFU-per $\mathrm{mg}$ ) were obtained from the Instituto Nacional de Producción de Biológicos A.N.L.I.S. Dr Carlos G. Malbrán, Buenos Aires, Argentina.

Tumor cell lines. T24, a human TCC line, was obtained from ATCC (Bethesda, MD) and cultured in MEM (41500, Gibco BRL) supplemented with $3 \mathrm{mM}$ L-glutamine, $80 \mu \mathrm{g} / \mathrm{ml}$ gentamycin and $8 \%$ fetal calf serum (FCS). Murine TCC lines MB49 (generously provided by Dr E.C. Lattime, Thomas Jefferson University, Philadelphia, PA) and MBT2 (kindly provided by T.L. Ratliff, University of Iowa, Iowa City, IA) were cultured in RPMI-1640 (Sigma, St. Louis, MO), also supplemented with glutamine, gentamycin and $10 \%$ FCS. Cultures were free of Mycoplasma as determined by periodic cytoplasmic DNA staining (the Hoechst method).

Chemical compounds and antibodies. Methylenediamine tetraacetic acid (EDTA), ethyleneglycol tetraacetic acid (EGTA), Brij, N-CBZ-Val-Lys-Lys-Arg-4-methoxy ß-naphtilaminde, nitroblue tetrazolium (NBT) and 5-bromo-4-chloro-3indolyl phosphate (BCIP), 3-aminophthalhydrazide (luminol), p-coumaric acid and Tris were obtained from Sigma Chemical Company (St. Louis, MO). The cell permeable CB inhibitor CA074-Me was purchased from Calbiochem (La Jolla, USA).

The Cell titer 96 AQueous, MTS was obtained from Promega Corporation (USA). Specific polyclonal anti-human CB antibody (sheep anti-hCB) was purchased from Serotec (Oxford, UK). Donkey anti-sheep IgG, conjugated with alkaline phosphatase was obtained from Biosyn Ltd. (Belfast, Ireland).

Rabbit polyclonal anti-murine CB (FL-339) sc-13985, antiBID (FL-195) sc-11423 and anti pro Caspase 9 P 35 (H-170)SC8355, were obtained from Santa Cruz Biotechnology, USA. Anti-actin antibody (Ab Mo 090M) was purchased from Biogenex (San Ramon, CA).

Determination of TCC line growth. Cell suspensions of $1 \times 10^{5}$ cells $/ \mathrm{ml}$ were seeded in 96-well $(200 \mu \mathrm{l})$ or in 6 -well plates (2 ml) (Greiner Labortechnik $\mathrm{GmbH}$, Frickenhausen, Germany) and cultured at $37^{\circ} \mathrm{C}$ in a $5 \% \mathrm{CO}_{2}$ humidified atmosphere up to $70-80 \%$ confluence ( $24 \mathrm{~h}$ of incubation). Different amounts of BCG (from 0.01 to $2 \mathrm{mg} / \mathrm{ml}$ ) were added for $2 \mathrm{~h}$ and then eliminated by washing with phosphate buffered solution. After $24 \mathrm{~h}$, cytostatic/cytotoxic effects were assessed by a non-radioactive cell titer MTS in 96-well plates, and by counting the number of cells in the 6-well plates.
Determination of apoptosis and necrosis. Tumor cells were seeded on cover slides in 6-well plates, treated with BCG $(2 \mathrm{mg} / \mathrm{ml}$ ) for $2 \mathrm{~h}$, and then washed. The $\mathrm{CB}$ catalytic inhibitor CA074Me (CA) $(10 \mu \mathrm{M})$ was also added. After $24 \mathrm{~h}$, cells adhered to cover slides and present in supernatants were stained with acridine orange $(10 \mu \mathrm{g} / \mathrm{ml})$ plus ethidium bromide $(10 \mu \mathrm{g} / \mathrm{ml})$. Cells with green fluorescence and condensed chromatin were recorded as apoptotic while orange cells with lax chromatin were recorded as necrotic cells.

Determination of $C B$ expression. Expression of $\mathrm{CB}$ was determined as previously described (16). Briefly, T24 and MB49 cell lines treated for $2 \mathrm{~h}$ either with or without BCG $(2 \mathrm{mg} / \mathrm{ml})$ were gently washed and after $24 \mathrm{~h}$ minced in buffer [50 mM Tris- $\mathrm{HCl}$ (pH 8.0); $100 \mu \mathrm{M} \mathrm{NaCl} ; 1 \%$ Triton, $1 \mu \mathrm{M} / \mathrm{ml}$ aprotinin, $1 \mathrm{mM}$ phenylmethylsulfonyl fluoride, $2 \mu \mathrm{g} /$ $\mathrm{ml}$ leupeptin and $10 \mathrm{mM}$ EDTA/EGTA] at approximately $30 \times 10^{6} \mathrm{cell} / \mathrm{ml}$. After disruption with two cycles of ultrasound, $80 \%$ of potency during $3 \mathrm{sec}$ (Vibra Cell ${ }^{\mathrm{TM}}$, Sonic and Matherials Inc., Danbury, CT, USA), samples were centrifuged for $10 \mathrm{~min}$ at $13,000 \mathrm{x}$ g. Protein content was determined in the resultant supernatant fluids by the Bradford method, $25 \mu \mathrm{g}$ of protein was heated at $95^{\circ} \mathrm{C}$ for $3 \mathrm{~min}$ in Laemmli buffer and electrophoresis was performed on $10 \%$ sodium dodecyl sulfate-polyacrylamide gel (SDS-PAGE) (17). Different concentrations of CB (12.5 and $25 \mu \mathrm{g} / \mathrm{ml})$ were simultaneously seeded. After electrophoresis, proteins were transferred to PVDF membranes and specific immunodetection was performed. Human and murine $\mathrm{CB}$ proteins were revealed with the NBT/BCIP and ECL method, respectively.

$C B$ activity assay. Activity of CB (EC: 3.4 .23 .1$)$ was determined in T24 and MB49 cell lines after 2, 4 and $24 \mathrm{~h}$ of treatment with or without BCG $(2 \mathrm{mg} / \mathrm{ml})$ by a colorimetric method (absorbance $520 \mathrm{~nm}$ ) as previously described by Barrett et al (18) employing a specific substrate (N-CBZVal-Lys-Lys-Arg-4-methoxy ß-naphtilaminde). Different concentrations of purified papain (EC: 3.47 .22 .2 ) were used to build a standard curve.

Determination of pro-caspase 9 and BID. Expression of both proteins was determined by Western blot assay. In this case only the human T24 and murine MB49 line were used. TCC cell lines were treated with BCG as described above with or without CA $(10 \mu \mathrm{M})$. At different times after BCG washing, cells were scraped and samples were prepared as previously described for the expression of CB. Samples were electrophoresed on $10 \%$ of SDS-PAGE and then transferred to PVDF membranes. Immunoreactive proteins were detected with the ECL method employing a solution of Tris $(0.1 \mathrm{M})$ plus luminol (124 mM), p-coumarinic acid (200 mM) and $\mathrm{H}_{2} \mathrm{O}_{2}$ (100 vol., 1:2500).

Statistical assays. Data were reported as mean \pm SD of four replicates per group. Significance of differences was calculated by one-way ANOVA and Bonferroni contrast by using Graph Pad InStat statistical package (version 3.01). Independent experiments were performed at least 3 times with similar results. Herein, we show one representative of three experiments. 

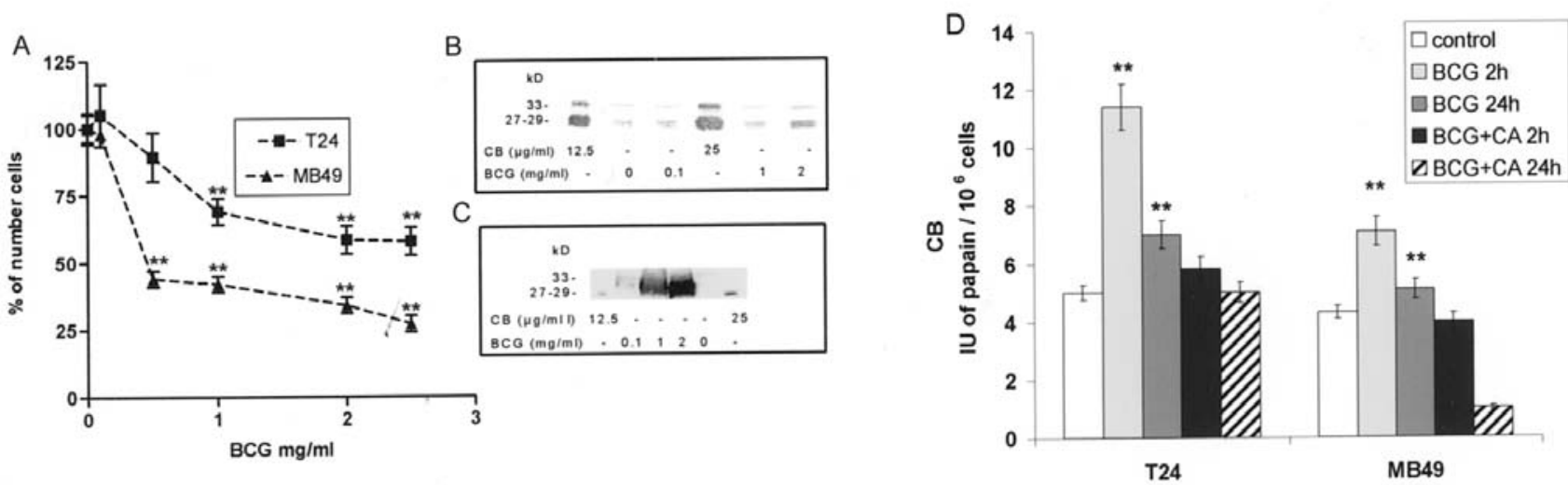

Figure 1. (A) Sub-confluent monolayers of T24 and MB49 cell lines treated with different BCG doses showed a significant inhibition of the cell number $\left({ }^{* *} \mathrm{p}<0.01\right)$. ID50 for MB49 was $0.5 \mathrm{mg} / \mathrm{ml}$ and for T24 was $>2.5 \mathrm{mg} / \mathrm{ml}$. (B) and (C) Western blot analysis for CB in T24 and MB49 cell lines, respectively. Purified human CB (12.5 and $25 \mu \mathrm{g} / \mathrm{ml}$ ) was used as control. (D) CB activity was increased as early as $2 \mathrm{~h}$ after BCG (2 mg/ml) addition, remaining elevated up to $24 \mathrm{~h}$ and was inhibited by $\mathrm{CA} .{ }^{* *} \mathrm{p}<0.01$ either vs. untreated cells or vs. BCG+CA treated cells.

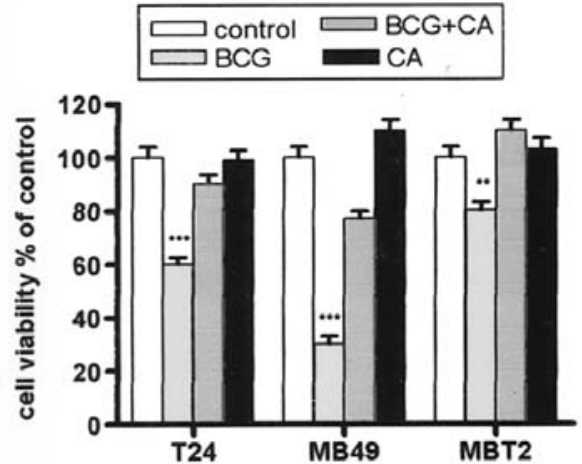

Figure 2. Inhibition of viability of TCC lines (MTS assay) after BCG (2 mg/ ml) treatment was blocked by $\mathrm{CA}(10 \mu \mathrm{M}) .{ }^{* *} \mathrm{p}<0.001,{ }^{* * *} \mathrm{p}<0.001 \mathrm{vs}$. control and vs. BCG+CA.

\section{Results}

In vitro inhibition of TCC growth by BCG. Subconfluent monolayers of bladder cancer cells treated with different concentrations of BCG showed a dose-dependent growth inhibition. Significant inhibition was observed for concentrations of $\mathrm{BCG} \geq 0.5$ and $1 \mathrm{mg} / \mathrm{ml}$ for $\mathrm{MB} 49$ and $\mathrm{T} 24$, respectively $(\mathrm{p}<0.01)$, being the ID50 for MB49 $0.5 \mathrm{mg} / \mathrm{ml}$, while for T24 cells it was even $>2.5 \mathrm{mg} / \mathrm{ml}$ (Fig. 1A).

$B C G$ induces an increase in both the expression and activity of $C B$ in TCC. Determination of intracellular CB with a specific antibody showed that both the human T24 and the murine MB49 cell lines expressed the 33-kDa single-stranded CB $\left(\mathrm{CB}_{33}\right)$ and the 29-27-kDa heavy chain of the double-stranded $\mathrm{CB}\left(\mathrm{CB}_{29-27}\right)$. Both $\mathrm{CB}_{33}$ and $\mathrm{CB}_{29-27}$ increased after $\mathrm{BCG}$ treatment (Fig. $1 B$ and $C$, respectively). Increase in $C B$ activity was observed as early as after $2 \mathrm{~h}$, remaining elevated up to $24 \mathrm{~h}(\mathrm{p}<0.01)$, and being inhibited by CA $(\mathrm{p}<0.01)$ (Fig. 1D).
$C B$ is involved in TCC growth inhibition induced by BCG. To investigate if $\mathrm{CB}$ was involved in BCG-induced cell growth inhibition, a new set of experiments were carried out with $\mathrm{CA}$, the $\mathrm{CB}$ cell permeable inhibitor. Fig. 2 shows that CA $(10 \mu \mathrm{M})$ blocked the inhibitory effect of BCG $(2 \mathrm{mg} / \mathrm{ml})$ on T24, MB49 $(\mathrm{p}<0.001)$ and MBT2 $(\mathrm{p}<0.01)$ cell viability, as determined by the MTS assay. Similar results were observed by cell number counting (data not shown). These results indicate that $\mathrm{CB}$ activity is involved in $\mathrm{BCG}^{\prime}$ s inhibitory effect.

BCG-induced TCC apoptosis is dependent on CB. After BCG treatment of T24, MB49 and MBT2 cells, apoptotic but not necrotic cells were observed (Fig. 3A). The percentage of apoptotic cells that remained adhered after BCG treatment was significantly higher than in controls $(\mathrm{p}<0.001)$, a result reversed by CA $(\mathrm{p}<0.05)$ (Fig. 3B1). Apoptotic cells were also recorded in supernatants showing similar results (Fig. 3B2). The results suggest that $\mathrm{CB}$ is involved in the induction of apoptosis by BCG.

$B I D$ and pro-caspase are activated by $C B$. To investigate whether the intrinsic pathway of apoptosis was activated by $\mathrm{CB}$, we measured the activation of BID and pro-caspase 9 in T24 and MB49 cells (Fig. 4). In MB49 cells, the expression of BID (p22) diminished between 2 and $4 \mathrm{~h}$, being undetectable 3-4 h later when truncated BID (p15) was expressed. CA inhibited the vanishing of p22 and the rise of p15 BID. Vanishing of pro-caspase 9 was detected after $1 \mathrm{~h}$ and this effect was also blocked by CA. Similar results were found in T24 cells (Fig. 4). Vanishing of BID (p22) started at $1 \mathrm{~h}$, but truncated p 15 could not be detected, and pro-caspase 9 was diminished up to $0.5 \mathrm{~h}$.

\section{Discussion}

Intravesical instillation of BCG is a standard therapy for superficial and in situ bladder carcinoma but its mechanism is not completely understood. Both immunological mechanisms and/or direct effects on tumor cells have been proposed, 

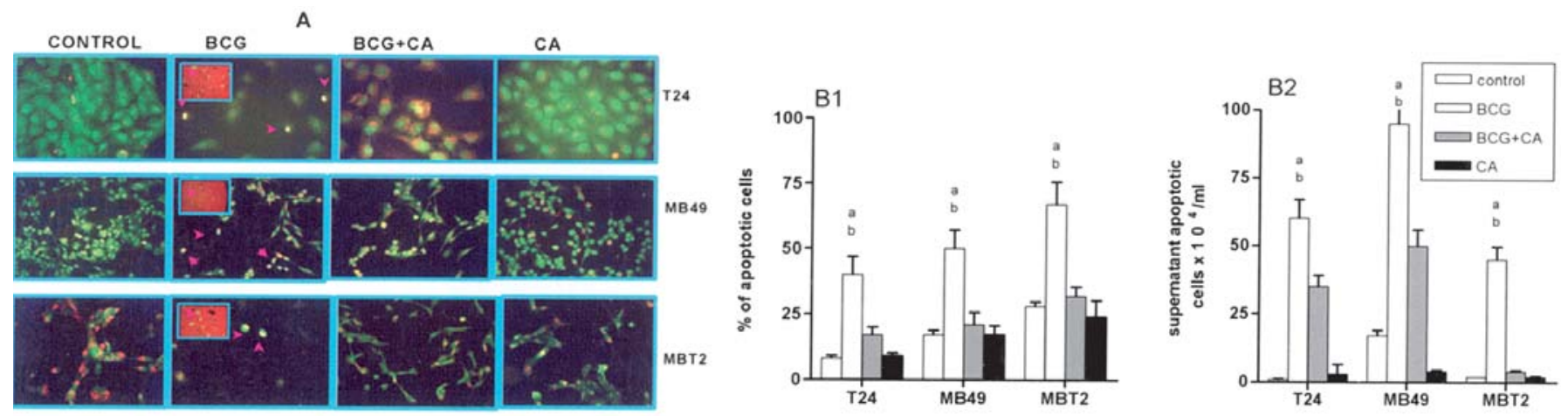

Figure 3. (A) Acridine Orange-Br Et staining of apoptotic cells in T24, MB49 and MBT2 monolayers without treatment (control) or treated with BCG (2 mg/ $\mathrm{ml}), \mathrm{BCG}+\mathrm{CA}$ or $\mathrm{CA}(10 \mu \mathrm{M})$. Arrows show apoptotic cells adhered or in supernatant (insert). (B1) Percentage of apoptotic cells remaining adhered, ${ }^{\mathrm{a}} \mathrm{p}<0.001,{ }^{\mathrm{b}} \mathrm{p}<0.05$ vs. control and vs. BCG+CA, respectively. (B2) Apoptotic cells were also higher in the supernatant of TCC treated with BCG than in controls $\left({ }^{\mathrm{a}} \mathrm{p}<0.001\right)$ and $\mathrm{BCG}+\mathrm{CA}\left({ }^{\mathrm{b}} \mathrm{p}<0.05\right)$

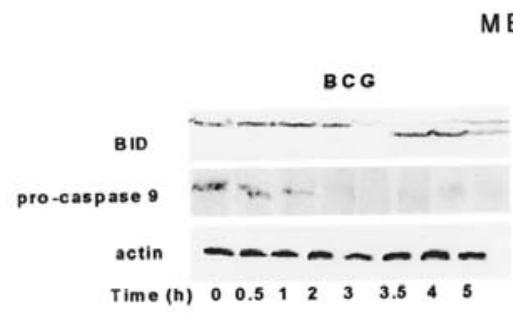

MB 49

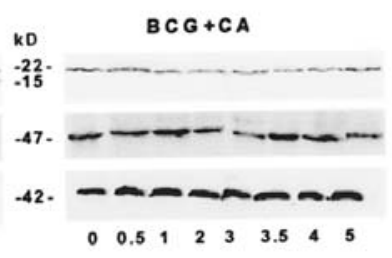

T24

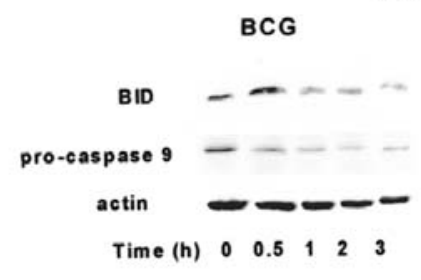

$B C G+C A$

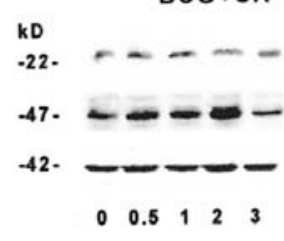

Figure 4. Western blot of BID and pro-caspase 9 expression at different times after BCG (2 mg/ml) and BCG+CA treatments of MB49 and T24 cell lines.

being the former more extensively studied. The direct effect on tumor cells has been less investigated in part because the immune therapy with BCG is administered after tumor resection, assuming that no tumor cells are present. However, it is possible that an undetectable number of tumor cells remain in the bladder. In light of our findings, the biological behavior of tumor cells to BCG could contribute to the global response. For example, it has been proposed that tumor cell death by apoptosis could be a better inducer of immunity than death by necrosis (19) and that dendritic cells loaded with apoptotic tumor cells are more efficient than dendritic cells loaded with necrotic ones in activating cytotoxic $\mathrm{T}$ lymphocytes (20).

Thus, we studied the effects of BCG on TCC lines by evaluating the participation of lysosomal hydrolase $\mathrm{CB}$ in apoptosis induction. BCG induced growth inhibition in a dose-dependent manner from $0.1 \mathrm{mg} / \mathrm{ml}$, reaching a plateau for doses $>2 \mathrm{mg} / \mathrm{ml}$. MB49 cells appeared to be more sensitive than T24 cells to BCG inhibition since the ID50s were $0.5 \mathrm{mg}$ / $\mathrm{ml}$ and $>2.5 \mathrm{mg} / \mathrm{ml}$, respectively. The $\mathrm{BCG}$ concentration used was in the therapeutic range, since $2 \times 10^{6} \mathrm{CFU} / \mathrm{ml}$ was indicated for human bladder instillation.

In agreement with other authors $(6,21)$, we observed that the T24 and MB49 cells were capable of internalizing BCG (data not shown). In addition, it has been reported that bladder tumor cells are capable of antigen presentation and induction of an immune response upon BCG treatment (6). As internalization and antigenic presentation depend on lysosomal pathway, and $\mathrm{CB}$ is the main lysosomal hydrolase involved in MHC II antigen presentation (22), we believe that $\mathrm{CB}$ could participate in the inhibition of cellular growth. CB protein increased concomitantly with inhibition of cell growth after BCG treatment. An increase in the 33- and 29$27-\mathrm{kDa}$ bands corresponding to the active forms of $\mathrm{CB}$ was detected. CB activity was also increased up to $2 \mathrm{~h}$ after BCG addition, and CA, a specific cell permeable CB inhibitor (23) blocked not only $\mathrm{CB}$ activity but also reversed BCG-induced cell growth inhibition. Thus, our results show that $\mathrm{CB}$ participates in the inhibition of TCC growth induced by BCG.

Since induction of apoptosis by different mycobacteria in other experimental models has been already described $(8,9)$ and that Mycobacterium Philei cell wall complex directly induces apoptosis in human bladder cancer cells (24), we studied whether BCG can also induce TCC apoptosis. Our results showed that BCG induced apoptosis in the three TCC lines assayed, and that $\mathrm{CB}$ participated in this process since it was blocked by CA.

Two initiation pathways, triggered by separate events, converge to execute apoptosis: the extrinsic one, which depends on extracellular binding to death receptors and activation of caspase 8 ; and the intrinsic one, which produces changes in the mitochondrial membrane potential with release of cytochrome $c$ and activation of pro-caspase 9 (25).

It has been described that $\mathrm{CB}$ contributes to hepatocyte apoptosis by promoting mitochondrial release of cytochrome $c$ (26). CB has also been involved in programmed death of human breast cancer cells MCF-7 by activating BID (26), suggesting that $\mathrm{CB}$ could participate in the intrinsic pathway. To test this possibility, we evaluated whether the activation of BID and pro-caspase 9 could be detected in our TCC cell lines. 
Our results showed that BCG induced activation of BID and pro-caspase 9 in both T24 and MB49 cells and that this induction was mediated by $\mathrm{CB}$ because it could be inhibited by CA. However, some points need further consideration. First, the kinetics of BID activation is different between MB49 and T24 lines. In MB49, BID begins to disappear at $2 \mathrm{~h}$ and is undetectable after $3 \mathrm{~h}$ or $3.5 \mathrm{~h}$, while in T24, a light vanishing was detected at $1 \mathrm{~h}$, which was constant for at least $6 \mathrm{~h}$ (data not shown). In MB49, truncated BID (p15) was detected at $3.5 \mathrm{~h}$ while in T24 it was undetected at least up to $6 \mathrm{~h}$ post-BCG addition (data not shown). This difference could be related to the fact that BCG-induced growth inhibition was higher in MB49 than in T24 lines. However, we cannot discard the fact that it can also be due to a different sensitivity of the antibody to murine and human cell lines. Second, our results showed that the activation of pro-caspase 9 precedes that of BID. If activation of BID by $\mathrm{CB}$ and the subsequent activation of the mitochondrial pathway were the only mechanisms, BID activation should precede pro-caspase 9 activation. Thus, other mechanisms must be involved in the activation of pro-caspase 9. Other proteins of the BID family such as Bax/Bak or other caspases could be involved in activating the mitochondrial pathway. For example, it has been reported that caspase- 2 may be responsible for direct permeabilization of mitochondria, while in other instances, it may act in conjunction with Bax/Bak to amplify cytochrome $c$ release $(27)$.

It has recently been published that proteasome inhibitors can induce $\mathrm{CB}$ release, caspase 2-dependent mitochondrial permeabilization and apoptosis in human pancreatic cancer cells (28). Furthermore, CB could be involved in the direct activation of pro-caspase 9 or, alternatively, as described in fibrosarcoma cell apoptosis induced by TNF (14), CB could act as a dominant executer protease inducing apoptosis of TCC.

Taken into account that apoptosis is a good inductor of immunity we can speculate that the patients whose tumor cells did not undergo apoptosis after BCG therapy, could be refractory or less sensible to this immune therapy. However, to arrive at this hypothesis it is necessary to know the complete mechanisms through which BCG exerts its antitumor activity. We propose that the increase in $\mathrm{CB}$ activity is involved in apoptosis of TCC lines induced by BCG. CB is able to activate BID and pro-caspase 9 , both proteins involved in the mitochondrial apoptotic pathway. The crosstalk between the extrinsic and mitochondrial apoptotic pathways as well as the participation of $\mathrm{CB}$ as a dominant executer protease awaits further investigation. To our knowledge, this is the first report showing that $\mathrm{CB}$ is involved in TCC apoptosis.

\section{Acknowledgements}

We thank Elisa Bal and Maria Adela Jasnis for their helpful comments and Guillermo Peluffo for language revision. Dr Ana María Eiján is a member of the Consejo Nacional de Investigaciones Científicas y Técnicas (CONICET). Catalina Lodillinsky is a Fellow of CONICET. This work was supported by the grant CONICET-PIP 5789 and UBACYT M015.

\section{References}

1. Malkowicz SB: Intravesical therapy for superficial bladder cancer. Semin Urol Oncol 18: 280-288, 2000.

2. Sylvester RJ, van der Meijden AP and Lamm DL: Intravesical bacillus Calmette-Guerin reduces the risk of progression in patients with superficial bladder cancer: a meta-analysis of the published results of randomized clinical trials. J Urol 168: 1964-1970, 2002.

3. Davis JW, Sheth SI, Doviak MJ and Schellhammer PF: Superficial bladder carcinoma treated with bacillus CalmetteGuerin: progression-free and disease specific survival with minimum 10-year follow up. J Urol 167: 494-500, 2002.

4. Suttmann H, Jacobsen M, Reiss K, Jocham D, Bohle A and Brandau S: Mechanisms of bacillus Calmette Guérin mediated natural killer cell activation. J Urol 172: 1490-1495, 2004.

5. Becich MJ, Carroll S and Ratliff TL: Internalization of bacilli Calmette-Guérin by bladder tumor cells. J Urol 145: 1316-1324, 1991.

6. Ikeda N, Toida I, Iwasaki A, Kawai K and Akaza H: Surface antigen expression on bladder tumor cells induced by bacillus Calmette-Guérin (BCG): A role of BCG internalization into tumor cells. Int J Urol 9: 29-35, 2002.

7. Alvarez V, Lodillinsky C, Umerez S, Sandes E and Eiján AM: Inhibition of bacillus Calmette-Guérin induced nitric oxide in bladder tumor cells may improve BCG treatment. Int J Mol Med 16: 565-571, 2005.

8. Riendeau $\mathrm{C}$ and Kornfeld $\mathrm{H}$ : THP1 cell apoptosis in response to Mycobacterial infection. Infect Immun 71: 254-259, 2003.

9. Weinrauch Y and Zychlinsky A: The induction of apoptosis by bacterial pathogens. Annu Rev Microbiol 53: 155-187, 1999.

10. Papageorgiou A, Lashinger L, Millikan R, Grossman HB, Benedict W, Dinney CP and McConkey DJ: Role of tumor necrosis factor-related apoptosis-inducing ligand in interferoninduced apoptosis in human bladder cancer cells. Cancer Res 64: 8973-8979, 2004.

11. Jäättelä M: Multiple cell death pathways as regulators of tumour initiation and progression. Oncogene 23: 2746-2756, 2004.

12. Jin Z and El-Deiry WS: Overview of cell death signaling pathways. Cancer Biol Ther 4: 139-163, 2005.

13. Guicciardi ME, Leist M and Gores GJ: Lysosomes in cell death. Oncogene 23: 2881-2890, 2004.

14. Foghsgaard L, Wissing D, Mauch D, Lademann U, Bastholm L, Boes M, Elling FM, Leist M and Jäätteelä M: Cathepsin B acts as a dominant execution protease in tumor cell apoptosis induced by tumor necrosis factor. J Cell Biology 153: 999-1010, 2001.

15. Lamparska-Przybysz M, Gajkowska B and Motyl T: Cathepsins and BID are involved in the molecular switch between apoptosis and autophagy in breast cancer MCF-7 cells exposed to camptothecin. J Physiol Pharmacol 56: 159-179, 2005.

16. Eiján AM, Sandes EO, Riveros MD, Thompson S, Pasik L, Malagrino H, Celeste F and Casabé AR: High expression of cathepsin B in transitional bladder cancer correlates with tumor invasion. Cancer 98: 262-268, 2003.

17. Laemmli UK: Cleavage of structural protein during the assembly of the head of bacteriophage T4. Nature 227: 680-685, 1970.

18. Barrett AJ and Kirschke H: Cathepsin B, cathepsin H and cathepsin L. Methods Enzymol 80: 535-561, 1981.

19. Goldszmid RS, Idoyaga J, Bravo AI, Steinman R, Mordoh J and Wainstok R: Dendritic cells charged with apoptotic tumor cells induce long-lived protective $\mathrm{CD} 4^{+}$and $\mathrm{CD}^{+} \mathrm{T}$ cell immunity against B16 melanome. J Immunol 171: 5940-5947, 2003.

20. Albert ML, Sauter B and Bhardwaj N: Dendritic cells acquire antigen from apoptotic cells and induce class I-restricted CTLs. Nature 392: 86-89, 1998.

21. Pook SH, Esuvaranathan K and Mahendran R: N-acetylcysteine augments the cellular redox changes and cytotoxic activity of internalized mycobacterium bovis in human bladder cancer cells. J Urol 168: 780-785, 2002.

22. Deussing J, Roth W, Saftig P, Peters C, Ploegh H and Villadangos JA: Cathepsins B and D are dispensable for major histocompatibility complex class II-mediated antigen presentation. Proc Natl Acad Sci USA 95: 4516-4521, 1998.

23. Buttle DJ, Murata M, Knight CG and Barrett AJ: CA074methyl ester: a proinhibitor for intracellular cathepsin B. Arch Biochem Biophys 299: 377-380, 1992.

24. Filion MC, Lépicier P, Morales A and Phillips NC: Mycobacterium phlei cell wall complex directly induces apoptosis in human bladder cancer cells. Br J Cancer 79: 229-235, 1999. 
25. Danial N and Korsmeyer SJ: Cell death: Critical control points. Cell 116: 205-219, 2004.

26. Guicciardi ME, Deussing J, Miyoshi H, Bronk SF, Svingen PA, Peters C, Kaufmann SH and Gores GJ: Cathepsin B contributes to TNF-alpha-mediated hepatocyte apoptosis by promoting mitochondrial release of cytochrome c. J Clin Invest 106: 1127-1137, 2000.
27. Enoksson M, Robertson JD, Gogvadze V, Bu P, Kropotov A, Zhivotovsky B and Orrenius S: Caspase-2 permeabilizes the outer mitochondrial membrane and disrupts the binding of cytochrome c to anionic phospholipids. J Biol Chem 279: 49575-49578, 2004.

28. Yeung BH, Huang DC and Sinicrope FA: PS-341 (bortezomib) induces lysosomal cathepsin B release and a caspase-2dependent mitochondrial permeabilization and apoptosis in human pancreatic cancer cells. J Biol Chem 281: 11923-11932, 2006. 